\section{"Viver dignamente": necessidades e demandas de saúde de homens trans em Salvador, Bahia, Brasil}

\author{
"Living with dignity": health needs and demands \\ of trans men in Salvador, Bahia State, Brazil
}

\author{
"Vivir dignamente": necesidades y demandas \\ de salud de hombres transexuales en Salvador, \\ Bahía, Brasil
}

Diogo Sousa 1

Jorge Iriart 1

\title{
Resumo
}

Este artigo discute as necessidades e demandas de saúde de homens trans, tema pouco estudado que, com frequência, interpela a construção de práticas de cuidado em saúde para esta população. Foi realizada uma pesquisa qualitativa composta de observação participante e entrevistas semiestruturadas com dez homens trans residentes em Salvador, Bahia, Brasil, em sua maioria negros, heterossexuais e com idades entre 20 e 43 anos. A análise foi baseada na antropologia interpretativa, articulada às críticas do pressuposto da interseccionalidade e da perspectiva decolonial. As necessidades e demandas de saúde dos homens trans são organizadas em três aspectos: a despatologização, a modificação corporal e os atendimentos ambulatoriais. Esses não são universais entre todos os homens trans e podem ser decorrentes de situações que assinalam conflitos e pressões grupais. A ausência do processo transexualizador no estado e as barreiras no acesso à rede de atenção à saúde intensificam o processo de mercantilização das suas demandas de saúde, em especial, as modificações corporais. Conclui-se que a transfobia estrutural faz disparar uma série de questões de saúde, ao mesmo tempo em que limita as possibilidades de obtenção de cuidado. A despatologização das vivências trans constitui o eixo central com base no qual o cuidado deve ser pensado, relacionando-a a mudanças culturais, politicas e sociais que impliquem a construção de uma sociedade não transfóbica e incidam no bem-estar e reconhecimento dos homens trans.

Necessidades e Demandas de Serviços de Saúde; Pessoas Transgênero; Direito à Saúde

\section{Correspondência}

D. Sousa

Instituto de Saúde Coletiva, Universidade Federal da Bahia. Rua Basílio da Gama 316, Salvador, BA 40110-040, Brasil. sousas.diogo@gmail.com

1 Instituto de Saúde Coletiva, Universidade Federal da Bahia, Salvador, Brasil. 


\section{Introdução}

As biografias dos homens trans têm possibilitado a expansão de múltiplas narrativas sobre sujeitos que, desafiando os pressupostos hegemônico-coloniais sobre corpo e gênero, revelam a incoerência da legitimação de padrões normativos em detrimento às vidas que não cessam de se reinventar. Os homens trans constroem arranjos entre sexo e gênero que ultrapassam a linearidade do padrão cisnormativo e ratificam outras possibilidades de conceber a constituição humana. Além dessa nomenclatura, eles também são conhecidos como trans homens, homens transexuais, homens transgêneros e FTM (female-to-male), podendo ainda existir outras possibilidades de reconhecimento não catalogadas.

Segundo Vergueiro 1, o padrão cisnormativo estabelece o reconhecimento e a legitimidade exclusivamente relacionados ao cumprimento de critérios em relação à cisgeneridade heterossexual. Isso significa cumprir a lógica una e linear que articula sexo e gênero na determinação de uma pessoa - como pênis-masculino-homem e vagina-feminino-mulher - fadada a experienciar a heterossexualidade. Ao contrário dessa articulação, o homem trans é a pessoa que nasce com vagina e constrói seu curso de vida como homem. Isso não lhe imputa a heteronormatização dos seus desejos.

Diversas discussões buscam romper com o caráter purista da categoria gênero, que tende a afirmar como masculinas ou femininas aquelas vivências que se alocam em suas determinações biológicas e sociais sem produzir fissuras 2,3 , ratificando a colonialidade com que a ciência tem organizado tais definições 4,5 e os riscos da sua universalização 4,6. Para os homens trans, novos borrões complexificam essa situação. O reconhecimento social como homem está colocado, principalmente, pela (re)produção e performance do gênero masculino baseado no padrão da identidade de gênero cisgênera e da sexualidade heterossexual, o padrão cisnormativo 1 , ou, adensando a crítica da heteronormatividade, cisheteronormativo.

Simone Ávila 7 destaca que as autobiografias e a produção de visibilidade pelos homens trans iniciaram ainda na década de 1970 com a publicação do livro Emergence: A Transexual Autobiography (1977), do ítalo-americano Mario Martino. Na década seguinte, além do lançamento do livro Erro de Pessoa, de João W. Nery, o primeiro homem trans brasileiro a realizar modificações corporais cirúrgicas, Lou Sullivan lançou, em 1986, o FTM Internacional Group, nos Estados Unidos. A aparição de Sullivan na mídia televisiva mobilizou homens trans de diferentes lugares, em especial, por dar sentido a uma experiência sobre a qual muitos não conheciam - nem se reconheciam.

A segunda metade do século XX foi responsável pelo exponencial crescimento das tecnologias em saúde, em especial daquelas com a finalidade de produzir modificações corporais aos soldados que voltavam mutilados das guerras. Elas inspiraram mulheres lésbicas masculinizadas (butches) na construção das suas performances de gênero ${ }^{8}$. Existe uma concordância de que esse contexto foi importante para que os homens trans elaborassem e requeressem estratégias de modificação corporal, uma vez que viram nessas novas tecnologias a possibilidade de construir o corpo e as performances de gênero desejados 7,8,9.

Questões de saúde passaram a ser dimensionadas. Evidentemente, elas estão diretamente relacionadas aos contextos culturais, sociais e políticos que propiciam mudanças capazes de assumi-las como importantes e garantir os meios de torná-las possíveis de satisfação. Destarte, ao reconhecermos a negação e a marginalização das vivências trans, buscamos, neste trabalho, compreender as necessidades e as demandas de saúde dos homens trans, considerando tratar-se de um passo primeiro para viabilizar caminhos por onde as estratégias de cuidado possam ser pensadas.

As demandas de saúde constituem pedidos explícitos, ou "traduções", de necessidades mais complexas do usuário, em grande parte, modeladas pela oferta que os serviços de saúde fazem - como a busca por consulta médica, consumo de medicamentos ou realização de exames. Já as necessidades representam a busca por uma "resposta às más condições de vida que a pessoa viveu ou está vivendo" 10 (p. 120). Quando acolhidas nos serviços de saúde, as necessidades e demandas tornam possíveis o reconhecimento das pessoas que chegam a estes espaços, marcadas por suas histórias e pelas relações que estabelecem. Cabe destacar que quando os modelos de saúde sustentam o foco na doença incorrese na construção de um sistema de saúde funcionalista e classificatório que não prevê a emancipação das mesmas ${ }^{11}$.

A ausência de pesquisas e indicadores epidemiológicos que expressem quadros de saúde dos homens trans constitui um empecilho para pensar estratégias de cuidados a serem implementados. 
Destarte, quando as necessidades e demandas de saúde de uma população são reconhecidas, as possibilidades de refletir as estratégias de garantia e de acesso aos cuidados ganham novos e potentes contornos 12,13 .

\section{Metodologia}

Baseamos nossa investigação nos pressupostos dos Estudos Decoloniais, reconhecendo que a inteligibilidade e a humanidade construídas para todos os sujeitos estiveram historicamente atreladas a padrões normativos que definiram critérios de superioridade e inferioridade organizados a partir da colonialidade do poder, do ser e do saber. Esse processo, baseado na dicotomização das experiências e sujeitos, valendo-se da formulação de critérios como raça, nacionalidade, religião, sexualidade e gênero, tornaram o homem branco europeu heterossexual cristão como modelo do humano e expeliu quaisquer outras possibilidades de existência da esfera do "real" 14. Em consonância com esse pensamento, Vergueiro ${ }^{1}$ apresenta a identidade de gênero também como critério colonial de dominação que definiu à população trans/travesti a ininteligibilidade e a produção de vidas precárias.

Realizamos uma pesquisa qualitativa, com entrevistas semiestruturadas feitas com dez homens trans residentes em Salvador, Bahia, Brasil, no período de julho a novembro de 2016. O contato com o campo da pesquisa aconteceu a partir da observação participante em eventos, congressos e espaços onde ocorriam discussões sobre transmasculinidades, possibilitando também compreender a construção das narrativas dos homens trans. Convites foram encaminhados em redes sociais virtuais e listas de e-mails, o que garantiu o contato com diversos homens trans que, com base nos critérios da pesquisa, tornaram-se participantes.

Os critérios de inclusão basearam-se na autodeclaração como homem trans, homem transgênero ou homem transexual, ter idade compreendida entre 20 e 43 anos e residir em Salvador. A autodeclaração como butch ou outra identidade masculina vivenciada por sujeitos que se reconheciam como mulheres, ter idade fora da faixa estabelecida e a residência em outro município constituíram os critérios de exclusão.

Os dois autores deste artigo são cisgêneros. O primeiro, homem cisgênero negro gay, foi responsável pela pesquisa e desenvolvimento do trabalho de campo. O segundo autor, homem cisgênero branco heterossexual, orientou o trabalho e a análise dos dados.

As entrevistas foram gravadas em dispositivo de áudio e transcritas, com média de 95 minutos de duração. O roteiro semiestruturado abordou os temas questões de saúde, construção de estratégias de cuidado e itinerários terapêuticos. As entrevistas foram previamente agendadas com os participantes e ocorreram em ambientes universitários, cafés no centro da cidade, em um espaço da rede de assistência do município e na casa de um participante. A análise dos dados baseou-se na Antropologia Interpretativa 15, visando a compreender e relacionar as dimensões da realidade vivida e significada pelos homens trans, adensada criticamente pelos pressupostos interseccionais e decoloniais.

Esta pesquisa foi avaliada e aprovada pelo Comitê de Ética em Pesquisa do Instituto de Saúde Coletiva da Universidade Federal da Bahia (CEP/ISC/UFBA), sob o parecer no 1.658 .899 e cumpriu as recomendações da Resolução no 466/2012, do Ministério da Saúde, e da Resolução no 510/2016, do Conselho Nacional de Saúde.

\section{Caracterização dos protagonistas da pesquisa}

Os dez protagonistas da pesquisa foram nomeados de Guilherme, Simon, Raí, Marcelo, Paulo, Caetano, Tom, Lucas, Ian e Leonardo. Suas idades variaram entre 20 e 43 anos. Paulo se autodeclarou pansexual, enquanto os demais homens trans afirmaram a heterossexualidade como orientação sexual. As ocupações apresentadas foram: aposentado, estudante, artista plástico, produtor cultural, vendedor, produtor de rádio e serviços gerais. A escolaridade variou entre o Ensino Fundamental completo, Ensino Médio completo, Ensino Técnico completo e Superior em curso. Sete dos protagonistas se autodeclararam negros, dois brancos e um (Paulo) não quis realizar a autodeclaração quanto à raça/ cor. Ele justificou não se reconhecer como homem branco, ainda que compreendesse que socialmente 
é lido como tal. Duas vertentes religiosas foram apresentadas, o Candomblé e o Espiritismo, embora afirmações de crença em Deus e Jesus também tenham sido referidas. Simon e Paulo apontaram não possuir religião.

\section{Resultados}

Todos os homens trans apontaram a transfobia quando perguntados sobre suas necessidades e demandas de saúde. A transfobia é uma faceta antidemocrática que finca limites para a compreensão das possibilidades de ser, definindo com base na patologização, na punição e na violência os cursos de vida que não se estabelecem a partir da cisheteronormatividade. Ela interage de modo singular e interseccional, além de demarcar que, em uma sociedade transfóbica, todos os homens trans estão sujeitos a sofrer violência. Esse arraigado e complexo mecanismo de violência e aversão às pessoas trans dimensiona e organiza os modos como se constituem as práticas de cuidado e as possibilidades de construção das estratégias que permitam aos homens trans alcançar soluções para as suas necessidades e demandas de saúde. Discutiremos três delas: a despatologização das vivências trans; as modificações corporais; e os atendimentos ambulatoriais.

\section{Despatologização das vivências trans}

A autorreferência como homens, o reconhecimento nas relações estabelecidas e a possibilidade de viverem dignamente constituem necessidades que organizam as questões de saúde dos homens trans. Esses tipos de reconhecimentos transitam entre elaborarem suas vivências diante de um contexto que invisibiliza ou anula informações sobre as transmasculinidades e a ausência de amparo legal que lhes permita encaminhar questões sem que sejam barrados por burocracias que não contemplam suas existências. Nos espaços de saúde, para terem suas identidades reconhecidas, os homens trans são compelidos a um processo de patologização. Apenas por meio de um laudo psicológico ou psiquiátrico passam a inscrever suas questões.

“...principalmente, no campo da saúde, né, pegam esse discurso dessa pessoa sem fazer essa análise disso pra legitimar essa necessidade de acompanhamento compulsório de dois anos por um psicólogo que vai tentar, o tempo todo, provar que você não é aquilo, que é uma fantasia" (Paulo, pansexual, 31 anos).

Esse reconhecimento baseia-se em um esfacelamento da pessoa que passa a ser lida como manifestação de uma doença. Todas as dimensões de cuidado que lhes são ofertadas, sejam os casos de hormonização, cirurgia ou as avaliações clínico-laboratoriais perpassam a patologização. De modo falho e falso, é a patologia que orienta o destino dos homens trans nos serviços de saúde. Essa situação se assemelha ao processo de "sidanização" de travestis com aids. Nele, os cuidados e as estratégias são pensados em função de uma doença, descaracterizando os marcadores sociais e contextos culturais que dimensionam as situações de vida dessa população 16 .

"Porque transexual tem CID e... como você já deve ter lido. Nos meus posicionamentos, eu não, eu tenho plena ciência da minha capacidade laboral, física, mental, psicológica e... eu não aceito um CID. Há quem diga que... a gente aproveita o CID porque existem os benefícios que a gente tem por conta da patologização, mas, eu não me vejo como doente, então, eu me identifico como homem transgênero ou homem trans, que é o termo que eu encontro pra fugir da patologização. Essa é a minha identidade" (Ian, branco, heterossexual, 25 anos).

Construir estratégias de cuidado aos homens trans implica a despatologização das vivências trans. Tal questão corresponde: (1) na retirada dessas experiências da Classificação Internacional de Doenças, 10a Revisão (CID-10), inscritas como F64.0 e F64.9, bem como das definições que patologizem essas vivências, como a disforia de gênero no Manual Diagnóstico e Estatístico de Transtornos Mentais, 5 a Edição (DSM-V); (2) à reorganização das práticas de cuidado, eliminando planos terapêuticos impositivos ou compulsórios, ou seja, a criação de estratégias que tomem como referências as experiências de pessoas trans, desconstruindo o padrão universal de ser humano assumido pelo campo da saúde; e (3) a reconhecer as pessoas trans em sua totalidade, garantindo-lhes plenos direitos e dirimindo as desigualdades decorrentes da transfobia.

Nos serviços de saúde, mesmo em situações baseadas em garantias estabelecidas por lei, como o respeito e a utilização do nome social, os entraves não são diminuídos: 
“Chegando lá [na emergência], falaram assim 'Já fez a ficha?', ela [Maria, a esposa]: 'Não', 'Então, vai lá fazer a ficha'. E a... a recepcionista que foi fazer a ficha, ela foi bastante inconveniente, né, porque eles pediram cartão do SUS com a identidade e, aí, ela [Maria] fala assim: 'Olha, eu vou te explicar: o cartão do SUS tá com o nome social', e ela [recepcionista] não sabia nem o que era o nome social, entendeu, então, tava muito mal informada. E aí, foi aí que ela [Maria] explicou pra ela o que era nome social: 'Não, se trata de homens trans e tal'. E ai ela [recepcionista] 'Trans?! Mas é igual aquela filha da Gretchen? Igual a Thammy?' (...) Aí, uma outra lá dentro da sala ficou rindo e falou 'É, menina, isso agora virou moda, isso agora é moda, não sabe como é que esse povo é?', a resposta que ela deu. (...) Depois, eu voltei e dei a resposta pra ela, que ela deveria de procurar se informar mais e ter respeito com, com as pessoas, não da maneira que ela colocou a situação, entendeu" (Guilherme, negro heterossexual, 39 anos).

A construção de um espaço de cuidado para os homens trans inclui a comunicação de informações de qualidade sobre o que é a transgeneridade e a diversidade com que ela se expressa, o que torna possível significar suas experiências reconhecendo-se com base em outras. Caetano nos apresenta essa situação, destacando barreiras socioterritoriais que produzem implicações nesse processo, bem como seus efeitos na elaboração das vivências pelos homens trans. Ele nomeia de "sapatrans masculinizados" as pessoas que vivem como lésbicas masculinizadas por não suporem a possibilidade de se reconhecerem como homens:

“...falta de informação. Isso você vê muito (...) em ambientes periféricos. Nós que temos acesso a isso, porque existe uma 'moqueca' de homens trans com visibilidade em Salvador (...). Se a gente sair do armário, fizer um trabalho de base de informação, muitos homens trans serão também [homens trans], que são 'sapatrans masculinizados"' (Caetano, negro heterossexual, 32 anos).

De igual modo, essas informações são importantes na formação e qualificação das/os profissionais de saúde em suas práticas. Tanto a compreensão sobre as transgeneridades, como também o modo de articular cuidados para as questões de saúde apresentadas pelos homens trans requerem instrumentalização e capacidade de relacionar técnicas que não produzam novos riscos. Paulo explica:

"A formação dos profissionais, de uma forma geral, especialmente das áreas de saúde, não tem essas discussões no currículo porque eles não sabem o que fazer. [Por exemplo:] eu tô lá com meu documento retificado, meu gênero retificado, eu vou no dermatologista e a dermatologista falava 'vamos fazer o uso do Roacutan', por exemplo, que é uma medicação que a pessoa não pode engravidar enquanto tá tomando ele. E, aí, eu fui falar que eu sou trans, que eu faço hormonioterapia, que eu tenho útero e que eu posso engravidar. Ela 'buga'. Ela não sabe o que fazer" (Paulo, pansexual, 31 anos).

\section{Modificação corporal}

As modificações corporais são procedimentos nos quais os homens trans visam a alcançar o corpo idealizado, muitas vezes, relacionado a um padrão de corpo cisgênero masculino. Do mesmo modo que as modificações corporais constituem estratégias de (re)produção do gênero a fim de possibilitar o reconhecimento e a aceitação em determinados contextos 17 para homens cis, elas também assumem importância similar no que diz respeito aos homens trans. Entretanto, elas não constituem demandas universais e não são igualmente requeridas entre os homens trans.

Cabe destacar que, para os homens trans, os efeitos que as modificações corporais garantem são, para além do reconhecimento, a aceitação e a proteção. Construir um corpo de homem que não porte ou expresse signos conhecidos como femininos evita uma série de violências em diversos contextos, em especial, os públicos. Contudo, destacamos que destinar todos os homens trans à construção de corpos lidos socialmente como masculinos (baseados, obrigatoriamente, na cisnormatividade) determina o tipo de autorização que têm para existir. Discutiremos as modificações corporais com base em três demandas: a hormonização, as cirurgias e os recursos culturais e sociais de construção do gênero desejado.

\section{Hormonização}

No período das entrevistas, cinco homens trans faziam uso de testosterona (Simon, Paulo, Caetano, Tom e Ian). Lucas havia começado a se hormonizar, mas interrompeu a prática para retomá-la no momento em que dispusesse de acompanhamento médico. Guilherme, Raí e Marcelo manifestavam 
interesse em dar início à hormonização. Leonardo indicou não querer realizar tal prática. Segundo Nery \& Maranhão-Filho 18, a hormonização constitui uma das principais demandas e a primeira modificação corporal que os homens trans realizam. A demanda pela hormonização surge como possibilidade de possuir no corpo e expressar por meio dele a masculinidade sentida e vivida.

Para os nove homens trans que se interessaram pela hormonização, a supressão dos caracteres secundários do sexo lidos socialmente como femininos e a aparição dos caracteres masculinos surgem como duas das principais razões para demandarem pelo processo. Segundo o Conselho Federal de Medicina 19 e o Centro de Bioética do Conselho Regional de Medicina de São Paulo 20, tal prática constitui uma importante estratégia terapêutica que minimiza o sofrimento de homens trans diante das mudanças corporais produzidas pelos seus próprios hormônios.

Para Leonardo, a recusa pelo uso de hormônios está relacionada com a possibilidade de engordar, situação que quer evitar. Nesse caso, a construção de um corpo masculino segue com outras preocupações, a partir do uso de roupas e do próprio comportamento. Almeida 21 afirma que existem homens trans que constroem seus corpos sem utilizar práticas hormonais ou cirúrgicas.

Paulo e Caetano dizem-se contra qualquer obrigatoriedade de hormonização para garantir a um homem trans o seu reconhecimento. Caetano, com cinco meses de hormonização à época da pesquisa, situa que os efeitos do uso da testosterona não podem ser balizadores do reconhecimento de uma pessoa como homem trans e que existem riscos para o corpo:

"Quando a gente menos espera, tá tudo ferrado por dentro. Porque você acha que ficar bonitinho tomando hormônio é o caminho pra todo mundo. Pra você ser homem, você não precisa tomar hormônio. Você tem que tomar hormônio se for apto, se seu corpo for apto pra receber aquilo" (Caetano, negro heterossexual, 32 anos).

Atrelada à hormonização está a avaliação e a assistência profissional para que esta prática não cause danos. Isso porque a qualidade do hormônio, o ciclo de realização, o modo como ele é aplicado e o acompanhamento do ciclo produzem questões e possíveis agravos à saúde dos homens trans.

"Porque quando eu fazia o ciclo de 21 dias eu não tinha tanta coisa. Eu sentia algo, nos 7 primeiros dias, aquela dor. Algo bem dolorido, mas depois não tinha nada e não via mudança nem fisicamente nem nada. Já com essa, eu já comecei a perceber que me transforma demais, tremedeira nas mãos, 'Ah, problema de coração, vai pro médico por quê??" (Tom, negro heterossexual, 20 anos).

O uso de hormônios constitui um ponto polêmico no processo transexualizador dada a ausência de regulamentação que garanta sua distribuição para usuárias/os do Sistema Único de Saúde (SUS), especialmente porque, no Brasil, a testosterona é um medicamento controlado. Isso não evita que práticas de hormonização ocorram por conta própria dos homens trans, implicando riscos em função de um plano terapêutico fragilizado 22. A prática organizada como terapia hormonal é apontada como segura a curto prazo e garante efeitos desejados, além de reduzir o risco de câncer de mama tanto a homens que realizaram a mamoplastia masculinizadora quanto àqueles que não optaram pelo procedimento 23 .

A hormonização é parte do percurso fundamental para a saúde e o bem-estar dos homens trans já que garante ganhos sociais diversos, incluindo o capital erótico que se expressa a partir desse novo corpo masculino 24. Entretanto, ela não pode ocorrer como constante processo de experimentação para os e nos homens trans, pois isto repercute em riscos e agravos à sua saúde. Assim, é preciso torná-la uma estratégia segura, capaz de produzir cuidados e melhorias na qualidade de vida dos mesmos, para evitar que ela se caracterize como causa mortis diante dos múltiplos impactos que produz.

\section{Cirurgias}

É verdade que portar determinado órgão genital que acompanha uma série de experiências corporais é uma questão para algumas pessoas trans e produz múltiplos sofrimentos, por isto, demandam práticas cirúrgicas como estratégias de cuidado. Mas, também é verdade que os discursos e critérios estabelecidos para o reconhecimento das identidades trans implicavam (e implicam) a reprodução de ojeriza pelo genital. Se as primeiras cirurgias transgenitalizadoras foram duramente criticadas e caracterizadas como contribuições médicas a práticas de mutilação, mesmo quando requeridas, é preciso destacarmos, hoje, a institucionalização de práticas cirúrgicas como única via de legitimação das vivências trans, desqualificando a pluralidade de experiências e os modos como cada corpo é 
construído. Condicionar o reconhecimento da identidade de gênero de pessoas trans a procedimentos cirúrgicos revela as múltiplas contradições e violências do dispositivo transexualizador 25 diante das vidas que não cessam de se reinventar.

Dentre os entrevistados, Paulo era o único que já havia realizado a mamoplastia masculinizadora, enquanto alguns dos demais se organizavam para tal. O termo mamoplastia masculinizadora, em substituição à mastectomia bilateral, sugere que, para o caso dos homens trans, a retirada das mamas não ocorre em função de neoplasias 18 . Leonardo não tinha certezas sobre a realização da mesma. Para muitos, a presença dos seios supõe a marcação do feminino em seus corpos, embora esta mesma condição não esteja posta para a vagina, sobre a qual questionam tal essencialização.

"A gente chama os seios de invasores. Porque é uma coisa que não faz parte da gente, a gente não vê como parte da gente. (...) tem coisas que é engessada, como a figura do homem esteticamente. Então, mesmo que a sociedade aceitasse um homem com... seios, pra gente não seria a figura ideal. Então, essa é uma, uma vontade, eu digo a você, com 99\% de certeza, de todo homem trans" (Ian, branco heterossexual, 25 anos).

A ausência de tecnologias que garantam a realização de uma transgenitalização segura para os homens trans, além do risco de perda de prazer, são as justificativas para a pouca busca deste procedimento. A histerectomia também surge no horizonte de possibilidades de transformação corporal, por vezes, englobando a salpingo-ooforectomia bilateral. Não houve menção para a realização de cirurgia facial, cirurgia de reconstrução do pomo de Adão, metoidioplastia ou neofaloplastia.

Embora tenhamos em vista que a produção do corpo masculino pode variar de pessoa para pessoa e eleger determinadas escolhas de modificação corporal em detrimento de outras, consideramos válido destacar que a legitimidade de cada vivência se faz a partir do momento em que é possível ter sua singularidade respeitada. Isso significa que a busca pelo corpo ideal apresentado por Ian e o recurso cirúrgico empregado neste processo é tão legítimo quanto a sua recusa, como faz Leonardo, evitando assim a ideia de incompletude que a cirurgia de transgenitalização impõe para muitas pessoas trans 26 . Por vezes, essas ideias baseadas no essencialismo de gênero são difundidas entre as próprias pessoas trans. Tom nos fala das pressões que sofre para realizar a mamoplastia masculinizadora que, por vezes, são mais incisivas que sua própria vontade:

"Hoje, eu acordo e durmo atormentado com a questão da mastectomia. Porque, teoricamente, é uma coisa que, se a sociedade fosse mente aberta, nem precisava fazer isso, é um dinheiro que você gasta, claro, vou me sentir bastante realizado quando eu fizer a mastectomia, mas, se você parar pra analisar, um dinheiro que eu não precisaria tirar, caso a sociedade te visse com outros olhos" (Tom, negro heterossexual, 20 anos).

Além da constituição do corpo que produza bem-estar físico e psíquico, os procedimentos cirúrgicos são demandados como vias para diminuir os riscos de agressão. Se as práticas de modificações corporais por eles realizadas implicam esconder ou eliminar características que remetam, metonimicamente, ao feminino, isto se dá porque elas podem ser determinantes para que os homens trans sofram violências. Em outras palavras, a demanda por cirurgia é uma via para alcançar o "momento de trégua" ou o "direito à indiferença" 21, a partir dos quais possam transitar sem correr riscos de ataques pela identificação de uma característica visível que produza ruptura com o padrão cisheteronormativo. Nesse sentido, Paulo nos diz:

"Tem violências, sabe, agressões, assim, tipo... você fica com medo de sair. Sair sozinho, à noite, tipo... Vou sair com amigo ou com o cara que eu tiver ficando... é... muito foda isso. E é pensar: eu quero o quê? Eu quero resolver só meu problema e conseguir minha passabilidade de machão, sabe, tipo, pra que não sofra mais? (...) Não quero só isso. Eu quero que todo mundo tenha direito de andar sem medo" (Paulo, pansexual, 31 anos).

Cabe destacar que a demanda pelas cirurgias destinadas à modificação corporal de pessoas trans tem o seu cuidado atrelado, por meio da rede pública de saúde, ao processo transexualizador. Desse modo, para que consigam realizá-las, os homens trans precisam iniciá-lo a partir dos 18 anos, passar por dois anos de acompanhamento terapêutico a fim de obter o laudo que lhe determine apresentar o CID F-64. Somente com base nesse diagnóstico será possível realizar as cirurgias por meio dos serviços públicos vinculados ao processo transexualizador. Cidades que ainda não têm o processo transexualizador implantado obrigam os homens trans a buscar alternativas em clínicas privadas, situação que leva suas demandas à condição de mercadorias. 


\section{Recursos sociais e culturais de produção do gênero}

Dos recursos mais utilizados e destacados pelos protagonistas da pesquisa na produção do gênero estão o binder/faixas, os cortes de cabelo, a utilização de vestuário específico e fármacos (principalmente, o Minoxidil, um vasodilatador utilizado para facilitar a saída da barba). Embora todos os protagonistas fizessem uso de vestimentas e apresentassem cortes de cabelo lidos socialmente como masculinos, estes recursos tornavam-se secundários ao serem dimensionadas a hormonização e a mamoplastia masculinizadora, mesmo entre aqueles que não haviam realizado quaisquer destas práticas.

Muitas vezes, a mudança nas vestimentas e os cortes de cabelo constituem a primeira prática de produção de gênero pelos homens trans. Isso nos fez considerar uma hierarquização das práticas de modificações corporais na qual aquelas que não produzem inscrições diretas no corpo ocupam espaços de menor destaque, mesmo que tenham importância na produção do gênero. O binder e outros tipos de faixas têm consequências físicas para os homens trans. Muitos ficam com hematomas na pele, além de falta de ar, possibilidade de fratura da coluna e displasia da mama. Raí chama a atenção para tais consequências:

"Os caras usam, muitas vezes, sem saber como utilizar. Existe um jeito certo de você colocar e existe um limite máximo de, de compressão. Tem caras que botam, que machuca, que fica sem ar, pode quebrar a costela, fraturar a costela e... ter vários outros problemas, respiratório, de coluna, postura, justamente por isso, e compromete também a cirurgia" (Raí, branco heterossexual, 21 anos).

Paulo, que já havia realizado a mamoplastia masculinizadora, revelou que situações de risco ainda acontecem e exigem cuidados e estratégias, como o uso de "volume" na região genital. Ele explica que, ao produzir a ideia de que possui um pênis, diminui a possibilidade de ser lido como homem trans - ou como um não homem - em situações de perigo, como assaltos. Casos de violências ocorridos tanto em contextos privados quanto públicos, com destaque para o ambiente familiar, escolar e de militância são comuns 7 .

Do mesmo modo que os homens trans demandam assistência quanto ao uso dos hormônios e das práticas cirúrgicas, eles necessitam que se produzam informações que garantam a assistência quanto ao uso de próteses, bem como novas tecnologias na produção de próteses de modo a diminuir os efeitos nocivos do seu uso.

\section{Atendimentos ambulatoriais}

Os exames clínicos e laboratoriais aparecem, na maioria das vezes, também relacionados às modificações corporais. Isso porque os homens trans, ao demandarem pela hormonização, entendem que seus corpos passarão por uma série de transformações que implicarão o modo como cada estratégia de cuidado, em especial, a biomédica, for proposta. Desse modo, demandam por acompanhamentos clínicos e exames laboratoriais que possibilitem leituras condizentes com as suas realidades, implicando os efeitos da hormonização e, também, das possíveis cirurgias.

Dentre as categorias profissionais demandadas pelos homens trans estão ginecologista, endocrinologista, psicóloga/o, clínica/o geral, nutricionista, médica/o cirurgiã/o, dermatologista, oftalmologista, otorrinolaringologista, psiquiatra e psicanalista. Das demandas por exames e procedimentos foram apresentados os exames laboratoriais e clínicos diversos, psicoterapia, hormonioterapia assistida, ultrassonografia, raio-x e cirurgias.

Ao implicarmos um olhar atento às questões relativas às modificações corporais, devemos considerar as significativas melhoras que elas incutirão em suas vivências, sem perder de vista que existem outras questões de saúde que são demandadas ao mesmo tempo. Nesse sentido, ao passo que lhes interessam a implantação do processo transexualizador no município (despatologizando a condução do mesmo), importa também que a rede esteja organizada para prover os cuidados necessários.

Por fim, todos os homens trans consideraram importante terem acesso à psicoterapia, seja para buscarem a compreensão de vivências e os sentidos das transmasculinidades, seja porque o contexto de violência que os envolve é vasto, partindo da família, dos espaços escolares, de saúde e dos demais espaços públicos e privados. Em 2013, o Conselho Federal de Psicologia apresentou nota técnica sobre o processo transexualizador 27 , a partir da qual considerou que a transexualidade e a travestili- 
dade não constituem condição psicopatológica, portanto, a assistência psicológica não deve se orientar em modelos patologizantes. Em 2018, lançou a Resolução CFP no 01/2018 28 que orienta o trabalho de psicólogas em relação a pessoas trans e travestis.

\section{Conclusão}

O cenário de intensa transfobia constitui um disparador de necessidades de saúde para os homens trans e adensa desafios para garantir a satisfação de suas demandas. Os recursos já disponíveis na rede de atenção à saúde não alcançam satisfatoriamente as questões dos homens trans porque seus corpos e suas experiências são deslegitimadas. Nesse sentido, urge incutirmos a despatologização das vivências trans, um processo diretamente relacionado com o combate à transfobia estrutural e institucional, superando as barreiras que se apresentam aos direitos das pessoas trans.

As necessidades e demandas de saúde dos homens trans visam a questões que estão para além de medidas setoriais de saúde. Elas explicitam melhores condições de vida, mudanças nos paradigmas culturais que enraízam desigualdades e das conjunturas sociais que permitam viver dignamente a partir das condições objetivas de existência da vida biológica, social e cultural 29. Isso foi bem colocado por Paulo (pansexual, 31 anos) quando afirma que sua necessidade de saúde é "conseguir ter acesso aos mesmos direitos [que as pessoas cisgêneras]. É conseguir dignidade, sabe? Viver dignamente".

O reconhecimento das necessidades e demandas de saúde dos homens trans dinamiza a responsabilidade da Saúde Pública quanto à integralidade, universalidade e equidade que impliquem a produção de estratégias de cuidado capazes de alcançá-los. Cabe ratificar os compromissos históricos e politicamente definidos pela garantia dos direitos à vida de pessoas trans por meio do Regime Internacional de Direitos Humanos das Nações Unidas, pelos princípios sobre a aplicação da legislação internacional de direitos humanos em relação à orientação sexual e identidade de gênero (Princípios de Yogyakarta) e pela Política Nacional de Saúde Integral de Lésbicas, Gays, Bissexuais, Travestis e Transexuais, além de efetivar a garantia ao nome social nos serviços de saúde e demais instâncias, dadas a Portaria MS no 1820, de 13 de agosto de 2009 e o Decreto PR no 8.727, de 28 de abril de 2016.

\section{Colaboradores}

D. Sousa foi responsável pela pesquisa, análise dos dados e escrita do artigo. J. Iriart orientou a pesquisa, análise dos dados e escrita do artigo.

\section{Agradecimentos}

D. Sousa contou com bolsa de estudos concedida pelo Programa de Excelência Acadêmica da Coordenação de Aperfeiçoamento de Pessoal de Nível Superior (Capes/PROEX). 


\section{Referências}

1. Vergueiro V. Por inflexões decoloniais de corpos e identidade de gênero inconformes: uma análise autoetnográfica da cisgeneridade como normatividade [Dissertação de Mestrado]. Salvador: Universidade Federal da Bahia; 2016.

2. Butler J. Gender as performance: an interview with Judith Butler. Radical Philosophy 1994; 67:32-9.

3. Connell R, Pearse R. Gênero: uma perspectiva global. São Paulo: nVersos; 2015.

4. Oyěwùmí $O$. Conceptualizing gender: the eurocentric foundations of feminist concepts and the challenge of African epistemologies. Dakar: Council for the Development of Social Science Research in Africa; 2004 (CODESRIA Gender Series, 1).

5. Lugones M. Rumo a um feminismo descolonial. Revista Estudos Feministas 2015; 22:93552.

6. Crenshaw K. Documento para o encontro de especialistas em aspectos da discriminação racial relativos ao gênero. Revista Estudos Feministas 2002; 10:171-88.

7. Ávila SN. FTM, transhomem, homem trans, trans, homem: a emergência de transmasculinidades no Brasil contemporâneo [Tese de Doutorado]. Florianópolis: Universidade Federal de Santa Catarina; 2014.

8. Preciado B. Manifiesto contra-sexual. Practicas subversivas de identidad sexual. Madrid: Editorial Opera Prima; 2002.

9. Áran M, Murta D. Do diagnóstico de transtorno de identidade de gênero às redescrições da experiência da transexualidade: uma reflexão sobre gênero, tecnologia e saúde. Physis (Rio J.) 2009; 19:15-41.

10. Cecilio LCO. As necessidades de saúde como conceito estruturante na luta pela integralidade e equidade na atenção em saúde. In: Pinheiro R, Mattos RA, organizadores. Os sentidos da integralidade na atenção e no cuidado à saúde. Rio de Janeiro: Instituto de Medicina Social, Universidade do Estado do Rio de Janeiro/Abrasco; 2009. p. 117-30.

11. Campos CMS, Bataieiro MO. Necessidades de saúde: uma análise da produção científica brasileira de 1990 a 2004. Interface Comun Saúde Educ 2007; 11:605-18.

12. Stotz EN. Os desafios para o SUS e a educação popular: uma análise baseada na dialética da satisfação das necessidades de saúde. In: Departamento de Gestão da Educação na Saúde, Secretaria de Gestão do Trabalho e da Educação na Saúde, Ministério da Saúde, organizador. VER-SUS Brasil: cadernos de textos. Brasília: Ministério da Saúde; 2004. p. 284-99.

13. Souza CR, Botazzo C. Construção social da demanda em saúde. Physis (Rio J.) 2013; 23:393413.

14. Mignolo WD. Histórias locais/projetos globais - colonialidade, saberes subalternos e pensamento liminar. Belo Horizonte: Editora UFMG; 2003.
15. Geertz C. A interpretação das culturas. Rio de Janeiro: LTC; 2008.

16. Pelúcio L. "Toda quebrada na plástica”: corporalidade e construção de gênero entre travestis paulistas. Campos 2005; 6:97-112.

17. Iriart JAB, Chaves JC, Orleans RG. Culto ao corpo e uso de anabolizantes entre praticantes de musculação. Cad Saúde Pública 2009; 25:773-82.

18. Nery JW, Maranhão-Filho EMA. Trans-homens: a distopia nos tecno-homens. In: Departamento de Apoio à Gestão Participativa, Secretaria de Gestão Estratégica e Participativa, Ministério da Saúde, organizador. Transexualidade e travestilidades na saúde. Brasília: Ministério da Saúde; 2015. p. 25-35.

19. Conselho Federal de Medicina. Parecer CFM $n^{\circ} 8 / 13$. Terapia hormonal para adolescentes travestis e transexuais. http://www.portalme dico.org.br/pareceres/CFM/2013/8_2013.pdf (acessado em 15/Mar/2016).

20. Centro de Bioética, Conselho Regional de Medicina de São Paulo. É ético prescrever hormonioterapia a adolescente transexual? http:// www.bioetica.org.br/? siteAcao=Faqs\&tipo $=\mathrm{f} \& \mathrm{id}=249$ (acessado em 20/Out/2016).

21. Almeida G. 'Homens trans': novos matizes na aquarela das masculinidades? Revista Estudos Feministas 2012; 20:513-23.

22. Lima F, Cruz KT. Os processos de hormonização e a produção do cuidado em saúde na transexualidade masculina. Sex Salud Soc 2016; (23):162-86

23. Irwig MS. Testosterone therapy for transgender men. Lancet Diabetes Endocrinol 2017; 5:301-11.

24. Tramontano L. Testosterona: as múltiplas faces de uma molécula [Tese de Doutorado]. Rio de Janeiro: Universidade do Estado do Rio de Janeiro; 2017.

25. Bento B. A reinvenção do corpo: sexualidade e gênero na experiência transexual. Rio de Janeiro: Garamond; 2006.

26. Almeida G, Murta D. Reflexões sobre a possibilidade da despatologização da transexualidade e a necessidade da assistência integral à saúde de transexuais no Brasil. Sex Salud Soc 2013; (14):380-407.

27. Conselho Federal de Psicologia. Nota técnica sobre o processo transexualizador e demais formas de assistência às pessoas trans. https:// site.cfp.org.br/wp-content/uploads/2013/09/ Nota-t\%C3\%A9cnicaprocesso-Trans.pdf (acessado em 10/Out/2016).

28. Conselho Federal de Psicologia. Resolução CFP no 01/2018. http://site.cfp.org.br/ wp-content/uploads/2018/01/Resolu\% C3\%A7\%C3\%A3o-CFP-01-2018.pdf (acessado em 15/Fev/2018).

29. Paim JS. Direito à saúde, cidadania e estado. In: Anais da 8a Conferência Nacional de Saúde. Brasília: Centro de Documentação do Ministério da Saúde; 1987. p. 45-59. 
Abstract

This article discusses the health needs and demands of trans men, a topic that has received little attention and frequently calls for the development of specific health care practices for this population. A qualitative study was performed, consisting of participant observation and semi-structured interviews with trans men residing in Salvador, Bahia State, Brazil, the majority of whom were black, heterosexual, and 20 to 43 years of age. The analysis was based on interpretative anthropology, linked to critique of the assumption of intersectionality and the decolonial perspective. The health needs and demands of trans men are organized in three aspects: de-pathologization, body modification, and outpatient care. These aspects are not universal among trans men and may result from situations that indicate group conflicts and pressures. The absence of transsexualization process in the state of Bahia and barriers to accessing the health care network intensify the commodification of trans men's health demands and especially body modifications. The study concludes that structural transphobia triggers a series of health issues, while limiting the possibilities for obtaining care. The de-pathologization of trans experiences constitutes the central basis for conceiving care, relating it to cultural, political, and social changes that involve the construction of a non-transphobic society and foster the well-being and recognition of trans men.

Health Services Needs and Demand; Transgender Persons; Right to Health

\section{Resumen}

Este artículo discute las necesidades y demandas de salud de hombres transexuales, tema poco estudiado que, con frecuencia, requiere la construcción de prácticas de cuidado de salud para esta población. Se realizó una investigación cualitativa, compuesta de diez hombres transexuales residentes en Salvador, Bahia, Brasil, en su mayoría negros, heterosexuales y con edades entre 20 y 43 años. El análisis se basó en la antropología interpretativa, vinculada a críticas del presupuesto de la interseccionalidad y desde una perspectiva decolonial. Las necesidades y demandas de salud de los hombres transexuales se organizan en torno a tres aspectos: despatologización, modificación corporal y atención ambulatoria. Estos no son universales entre todos los hombres transexuales y pueden derivarse de situaciones que indican conflictos y presiones grupales. La ausencia del proceso transexualizador en el estado y las barreras en el acceso a la red de atención de la salud intensifican el proceso de mercantilización de sus demandas de salud, en especial, las modificaciones corporales. Se concluye que la transfobia estructural dispara una serie de cuestiones de salud, al mismo tiempo que limita las posibilidades de obtención de cuidado. La despatologización de las vivencias trans constituye el eje central, en base al cual se debe pensar el cuidado, relacionándolo con cambios culturales y políticas sociales que impliquen la construcción de una sociedad no transfóbica e incidan en el bienestar y reconocimiento de los hombres transexuales.

Necesidades y Demandas de Servicios de Salud; Personas Transgénero; Derecho a la Salud
Recebido em 26/Fev/2018

Versão final reapresentada em 18/Mai/2018

Aprovado em 25/Mai/2018 